\title{
CULTURA Y SOCIEDAD
}

\author{
La expansión española en Asia Oriental \\ en el siglo $x v I$ : motivaciones y resultados
}

\author{
JOSÉ ANTONIO CERVERA \\ El Colegio de México
}

\section{Introducción}

En las últimas décadas, con la emergencia de los países de Asia Oriental y el nuevo rol que China está adquiriendo internacionalmente en la economía y en la política, hay una fascinación por recuperar la historia compartida a un lado y otro del océano Pacífico. El tema de la ruta del Galeón de Manila está suscitando cada vez más interés, no sólo entre los especialistas, sino también entre el público en general. En los últimos años se han realizado en España, en México y en Filipinas varios simposios y congresos internacionales para celebrar diversas efemérides, como los 500 años del nacimiento de Andrés de Urdaneta (en 2008), el quinto centenario del "hallazgo" del Pacífico (en 2013) o los 450 años de la llegada de Legazpi a Filipinas y el posterior tornaviaje (en 2015). Gracias a estos eventos y a la aparición de numerosas publicaciones, algunos de los temas que parecían claramente establecidos, como el "descubrimiento" del tornaviaje de Asia a América, están siendo revisados.

El presente artículo no pretende realizar una aportación original al tema, sino retomar algunas de las últimas investigaciones llevadas a cabo por los especialistas y hacer un compendio sobre cómo se entiende hoy la expansión hispana por el Pacífico durante el siglo Xvi y el establecimiento en Filipinas, con los ojos puestos en el redituable comercio de las especias y en las aspiraciones españolas hacia el imperio chino. 


\section{En la búsqueda de la ruta de las especias}

Además de ser la primera navegación alrededor del mundo, el conocido viaje de Magallanes y Elcano (1519-1522) supuso para los españoles la apertura de la ruta a Asia Oriental. ${ }^{1}$ La nao Victoria, al llegar a Sanlúcar de Barrameda tras el largo periplo, llevaba un cargamento de clavo cuya venta cubrió los gastos de la expedición. Este detalle muestra la importancia del comercio de las especias desde el primer momento. Tanto Portugal como Castilla pretendían el derecho sobre las Molucas, lugar de producción de las especias más caras. Los portugueses habían sido los primeros en llegar a la zona. En 1511, Alfonso de Albuquerque conquistó Malaca, una de las ciudades clave del comercio asiático que, por su privilegiada situación geográfica, se había convertido durante el siglo XV en el lugar donde convergían mercaderes chinos, indios, árabes y malayos. Tan sólo un año después, en 1512, los portugueses se posesionaron de las Molucas, las preciadas islas de la Especiería.

En 1524, Carlos I mandó una gran flota a la zona, la segunda expedición española a Asia Oriental. Dirigida por García Jofre de Loaisa y compuesta por siete navíos, partió, en julio de 1525, del puerto de La Coruña. El viaje a través del océano $\mathrm{Pa}$ cífico fue desastroso. Los ciento cinco sobrevivientes - de los cuatrocientos cinco iniciales- finalmente llegaron a Mindanao y, posteriormente, a las preciadas Molucas. Durante los siguientes años, españoles y portugueses lucharon por el control de estas islas.

Las expediciones de Magallanes y Loaisa fueron las dos primeras y las únicas que partieron de la península ibérica para Asia Oriental. La tercera saldría ya desde la Nueva España. Her-

${ }^{1}$ Las expediciones españolas por el Pacífico durante el siglo XVI están tratadas en numerosas obras. Algunas de éstas son: Juan Gil, Mitos y Utopías del Descubrimiento, vol. 2: El Pacífico, Madrid, Alianza Editorial, 1989; Antonio Rumeu de Armas, El tratado de Tordesillas, Madrid, Mapfre, 1992; Salvador Bernabéu, El Pacífico Ilustrado: Del lago español a las grandes expediciones, Madrid, Mapfre, 1992; Patricio Hidalgo, Los primeros de Filipinas. Crónicas de la conquista del archipiélago, Madrid, Miraguano y Polifemo, 1995; Lothar Knauth, "La cuenca del Pacífico: ¿...Una historia recuperada?”, en G. Cruz, C. Barrón, A. del Castillo y C. Hernández (coords.), El Galeón de Manila. Un mar de historias, México, JGH Editores, 1997; o Cristina Barrón (coord.), Urdaneta novohispano. La inserción del mundo hispano en Asia, México, Universidad Iberoamericana, 2012. Los datos que aparecen en este apartado provienen de esas obras. 
nán Cortés, que se había enterado del viaje de Loaisa, designó a Álvaro Saavedra Cerón para dirigir un viaje a las Molucas. La nueva expedición partió del puerto de Zihuatanejo, en octubre de 1527. Tras un viaje accidentado, logró llegar a la pequeña isla de Tidore y ayudar a los castellanos que quedaban allí como sobrevivientes de la expedición de Loaisa. Sin embargo, los intentos para volver a la Nueva España cruzando el Pacífico no tuvieron éxito.

Debido a la imposibilidad de los españoles de volver al continente americano desde las Molucas, y ante la consiguiente falta de noticias en España, Carlos I decidió renunciar a los derechos castellanos sobre esta zona del mundo para centrarse en su imperio americano y en sus propios intereses en Europa, empeñando sus presuntos derechos sobre las islas de la Especiería en el tratado de Zaragoza, en 1529. Mediante este tratado, el rey de España cedía al monarca portugués el derecho de posesión y el derecho a navegar y comerciar en toda la zona al oeste de un meridiano situado a 17 grados al este de las Molucas, a cambio de trescientos cincuenta mil ducados de oro. Según el tratado de $\mathrm{Za}$ ragoza, tanto las Molucas como Filipinas se encontraban de manera clara en la zona empeñada por el rey de España al soberano portugués.

Tras el empeño, la presencia española en las Molucas dejaba de tener sentido. A pesar de ello, en los siguientes años todavía hubo dos expediciones españolas a la zona desde la Nueva España. La primera, dirigida por Hernando Grijalva, entre 1536 y 1537, partió del puerto peruano de Paita rumbo al oeste. Siguió prácticamente la ruta del ecuador hasta llegar a la zona de Nueva Guinea. La siguiente expedición fue confiada por el virrey novohispano a Ruy López de Villalobos. Tras llegar a Mindanao y a otras islas del archipiélago filipino, a principios de 1543, fueron a las Molucas. En 1546, los supervivientes intentaron volver a la Nueva España en dos ocasiones, sin éxito. Finalmente, los restos de la expedición llegaron a España, en 1547, tras circunnavegar India y África.

En 1559, tan sólo tres años después de subir al trono, Felipe II retomó las aspiraciones españolas sobre el sureste de Asia y envió una real cédula al virrey de la Nueva España, Luis de Velasco, para que preparara un viaje a Filipinas (con prohibición 
expresa de ir a las Molucas). La expedición estuvo al mando del guipuzcoano Miguel López de Legazpi y sería la que finalmente establecería una colonia española permanente en Asia.

Tradicionalmente se ha considerado que el interés de Felipe II para llegar a Asia Oriental tenía el objetivo de entrar en el lucrativo negocio de las especias; sin embargo, Patricio Hidalgo tiene una tesis más sugerente. Según él:

[...] la incorporación de Filipinas al imperio español tenía su origen en el descubrimiento de las minas de plata a partir de la cuarta década del siglo XVI y en el negocio que suponía una plata devaluada en América pero sobrevaluada en Asia, lo que permitía comprar productos asiáticos a un precio muy bajo y venderlos luego en América y Europa con un inmenso margen de beneficio. [...] ello llevó a Carlos $\mathrm{V}$ y después a Felipe II a romper por la fuerza el tratado de Zaragoza de 1529 y conseguir así una base estratégica frente al mundo asiático en un momento en que en América se estaban descubriendo las minas de plata. Fruto de ello fueron las expediciones de Villalobos en 1542 y la definitiva de Legazpi en 1564. Serían, pues, las inmensas posibilidades económicas las que explicasen el deseo castellano de establecerse en las Filipinas, a sabiendas de que éstas caían dentro del empeño. ${ }^{2}$

La hipótesis es interesante, porque muestra que, desde el principio, uno de los objetivos de los españoles era llegar a China, donde la plata era más demandada, usando Filipinas como una etapa intermedia. La opción de China desde una época tan temprana, además, permite entender por qué la relación con Asia a través del Pacífico se centró en la Nueva España. Además del virreinato novohispano, sólo Perú tenía abundancia de plata, pero este último tenía las desventajas de encontrarse mucho más lejos de España, de no tener maderas resistentes en sus costas, y de haber vivido una conquista y colonización más tardía que la de México. Desde cualquier punto de vista, y sobre todo debido a la gran cantidad de plata que ya se estaba extrayendo, el virreinato de la Nueva España era el punto ideal para servir de puente entre España y Asia Oriental. ${ }^{3}$

${ }^{2}$ Patricio Hidalgo, "La figura de Andrés de Urdaneta en la historiografía indiana, conventual, documental y moderna", en S. Truchuelo (ed.), Andrés de Urdaneta: un hombre moderno, Ordizia, Ayuntamiento de Ordizia, 2009, p. 67.

${ }_{3}^{3}$ Ostwald Sales, El movimiento portuario de Acapulco. El protagonismo de Nueva España en la relación con Filipinas, 1587-1648, México, Plaza y Valdés, 2000, pp. 53-54. 
La flota, compuesta por cinco barcos, zarpó del puerto de la Navidad el 21 de noviembre de 1564. Tras fondear en varias islas del Pacífico, llegaba a Filipinas, concretamente a la isla de Tubabao (en las costas de Samar) el 13 de febrero y posteriormente a Cebú el 27 de abril del mismo año, para establecer allí el primer asentamiento permanente en las islas Filipinas.

La expedición de vuelta a la Nueva España fue dirigida por Felipe de Salcedo, de 18 años, nieto de López de Legazpi, aunque el responsable no era otro que el navegante agustino Andrés de Urdaneta. El 1 de junio de 1565 partió del puerto de Cebú la nave San Pedro. El derrotero que siguió Urdaneta desde Filipinas se dirigía hacia el norte, casi bordeando Japón, para llegar a los 38 o 40 grados de latitud norte. El 8 de octubre llegaron a Acapulco. Éste fue el primer viaje confirmado de Asia a América a través del océano Pacífico. Tras este primer tornaviaje pudo establecerse, unos años después, la famosa ruta del Galeón de Manila o Nao de China.

En los últimos años se ha suscitado una controversia relacionada con el establecimiento de los españoles en Filipinas. Tras décadas de atribuir el "descubrimiento" del tornaviaje al genio aislado de Urdaneta, últimamente parece probado que los conocimientos eran compartidos por un amplio grupo de hombres en la Nueva España. ${ }^{4}$ Otra de las polémicas historiográficas que se suscitó ya hace décadas es la posible existencia de un tornaviaje anterior al de Urdaneta. ${ }^{5}$ Hoy parece bastante claro que Alfonso de Arellano cruzó el Pacífico antes que Urdaneta, pero eso no le quita el mérito al agustino vasco sobre el establecimiento de la ruta transpacífica.

${ }^{4}$ Algunos de los autores que han abogado por la idea de quitar cierto mérito a Urdaneta y considerar el tornaviaje como una empresa colectiva son: Luis Abraham Barandica, "Andrés de Urdaneta en la Nueva España (1538-1568)”, en Barrón (coord.), Urdaneta novohispano, op. cit., pp. 35-65, o Juan Gil, "El primer tornaviaje", en S. Bernabéu (coord.), La nao de China, 1565-1815. Navegación, comercio e intercambios culturales, Sevilla, Universidad de Sevilla, 2013, pp. 25-64.

${ }^{5}$ Existen evidencias claras de que el San Lucas, un patache pequeño capitaneado por Alfonso de Arellano y que formaba parte de la flota de Legazpi cuando ésta partió de América, en noviembre de 1564, pudo haber completado el viaje hasta Mindanao, y regresar al puerto de la Navidad el 9 de agosto de 1565, dos meses antes que el propio Urdaneta. 


\section{Destino: China}

Cuando los españoles llegaron a Filipinas, encontraron una red establecida de rutas mercantiles usadas por comunidades chinas $y$ japonesas que iban a comerciar con los antiguos sultanatos musulmanes de la zona. El sureste asiático era un ámbito donde existía desde hacía siglos una gran circulación de minorías mercantiles y dirigentes, sobre todo de origen iraní o indio. Hay obras chinas de dinastías anteriores a la Ming que describen claramente las relaciones de China con Filipinas, como la Relación de los países extranjeros (Zhang Rukuo, dinastía Song) y la Relación de los países e islas de ultramar (Wang Dayuan, dinastía Yuan). ${ }^{6}$

Durante la dinastía Ming, existió un gran movimiento migratorio de chinos hacia el sureste de Asia. En 1567 se aprobaba para Fujian una política de apertura marítima, kaibai, que relajaba la anterior prohibición del mar (baijin) y permitía la libre salida de los juncos chinos. Esta apertura china hacia el comercio exterior coincidió con la llegada de los primeros europeos a las costas del sur de China. Los españoles y los portugueses en un primer momento, y los holandeses después, tomarían el papel de intermediarios en las relaciones comerciales de la zona. En sus manos estaría buena parte del comercio entre China y Japón, a través de Macao y Nagasaki, así como el aporte de metales preciosos, para lo cual Manila sería el punto de encuentro con América y el ámbito atlántico.

Los españoles llegaron a Filipinas en un momento especialmente propicio para comerciar con China. ${ }^{7}$ No sólo se habían relajado las anteriores restricciones para el comercio marítimo,

${ }^{6}$ Zhang Kai, Historia de las relaciones sino-españolas, Beijing, Elephant Press, 2003 , p. 73.

${ }^{7}$ La hipótesis de que los españoles estaban interesados en establecerse en la China continental durante la segunda mitad del siglo Xvi ha sido tratada ampliamente por Manel Ollé, a quien se le reconoce internacionalmente como el mejor conocedor de este tema. Entre sus numerosas obras pueden citarse las siguientes: La invención de China. Percepciones y estrategias filipinas respecto a China durante el siglo XVI, Wiesbaden, Harrassowitz Verlag, 2000; La empresa de China. De la Armada Invencible al Galeón de Manila, Barcelona, Acantilado, 2002; y, más recientemente, "La proyección de Fujien en Manila: los sangleyes del Parián y el comercio de la Nao de China”, en S. Bernabéu y C. Martínez Shaw (eds.), Un océano de seda y plata: el universo económico del Galeón de Manila, Sevilla, Consejo Superior de Investigaciones Científicas, 2013, pp. 155-178. 
sino que la plata, metal precioso con una enorme producción en América, tenía una gran demanda y por lo tanto estaba sobrevaluada. La venta de plata a los chinos se convirtió en un negocio con enormes beneficios. Además, debido a que en China se producía prácticamente todo, los españoles fueron conscientes muy pronto de que casi lo único que podían ofrecer a China a cambio de sus mercancías era plata:

[...] vna de las difficultades queste trato y comerçio tiene es que desta tierra ni despaña, asta lo que agora sentiende, no se les puede lleuar nada, que ellos no tengan, porque tienen abundancia de sedas y lençería: dizen asimismo que la tienen; paños, por ser la tierra caliente, no los gastan ni los tienen en nada; açúcar, ay gran abundançia; çera y drogas y algodón en las islas ay gran cantidad, a donde ellos lo uienen a rrescatar. Por manera que se viene a resumir que la contrataçión desta tierra á de ser con plata, que es lo que ellos más estiman. ${ }^{8}$

En los primeros años de presencia hispana en Filipinas, los castellanos estaban establecidos en las Visayas, principalmente en Cebú y Panay. Parece bastante claro que el archipiélago filipino, en los primeros años, era considerado como una simple etapa transitoria, una plataforma para llegar al verdadero objetivo. Pero ¿cuál era ese objetivo? ¿Las islas de la Especiería, que habían marcado desde el principio toda la empresa de expansión castellana? ¿O el gran imperio de la China? Dependiendo de cuál de los dos objetivos se considerara más importante, convendría escoger el asentamiento principal en el archipiélago. En ese primer momento, en Filipinas, los españoles se encontraban ante una disyuntiva: ¿se debía seguir en Cebú, lugar más adecuado para explotar las especias de las Molucas, o bien trasladarse a la bahía de Manila, mejor situada para el comercio con China? La duda aparece explícitamente en una carta escrita por Legazpi, el 25 de julio de 1570, y dirigida al virrey novohispano:

También querría estar çierto de la voluntad de su magestad si é de cobrar a maluco y lo que más le perteneçe de aquella parte, porque para esto está más cómodo el asiento de çubú que otro por la bondad del puerto,

8 "Carta del virrey de la Nueva España, Martín Enríquez, a Felipe II, 5 de diciembre de 1573”, AHN, Doc. Ind., Secc. Div., núm. 219. 
pero si su magestad pretende que sus ministros se estiendan a la parte del norte y costa de china, tengo por más açertado hazer asiento en la ysla de luçón, de donde vino agora el maestre de campo, donde descubrió vn puerto, avnque pequeño, pero cómodo para media doçena de navíos, legua y media del pueblo de manilla, cabezera de toda aquella provinçia. ${ }^{9}$

Al año siguiente, en 1571, Legazpi trasladó el asentamiento principal de los españoles de Cebú a Manila. Este hecho responde la disyuntiva anterior. Como habían hecho tras el tratado de Zaragoza, los españoles renunciaron a la pretensión de establecerse en las Molucas (al menos al principio, ya que a principios del siglo XVII sí que hubo una expedición española a las islas de las especias) y se optó por una mayor cercanía a China. Esta especie de victoria de la opción de China, realmente importante para entender la historia de Filipinas, hoy es reconocida por la mayor parte de los investigadores. ${ }^{10}$

\section{Conclusión}

La motivación fundamental para trasladar a Manila el asentamiento principal en el archipiélago fue la posibilidad del comercio con los chinos, lo cual proporcionaba a los españoles seguridad para su continuidad en Filipinas, que no habían tenido en sus precarios asentamientos anteriores en Cebú y Panay. La zona de Manila estaba situada dentro de las rutas comerciales existentes antes de la llegada de los europeos a Asia Oriental. La llegada de los españoles a Filipinas coincidió en el tiempo con un cambio de la política china hacia el comercio exterior marítimo, al suavizar la política de haijin (prohibición del mar), lo que promovió la llegada de comerciantes chinos, sobre todo procedentes de Fujian, a todo el sureste asiático.

9 “Carta de Legazpi al virrey de Nueva España, Panay, 25 de julio de 1570”, AGI, Patronato, 24.

${ }^{10}$ Así lo aseveran, por ejemplo, entre otros, Ollé, La empresa de China, op. cit., p. 46; José Ramón de Miguel, Urdaneta y su tiempo, Ordizia, Ayuntamiento de Ordizia, 2008, p. 125; Dolors Folch, "Biografía de Fray Martín de Rada", Revista Huarte de San Juan, Geografía e Historia, núm. 15, 2008, p. 45, y Jean-Nöel Sánchez, “Tiempos Malucos. España y sus Islas de las Especias, 1565-1663”, en Truchuelo (ed.), Andrés de Urdaneta: un hombre moderno, op. cit., p. 624. 
A principios de los años setenta del siglo XVI, tuvo lugar el auténtico inicio de las relaciones entre los españoles y los sangleyes (término con el que se conocía a los chinos en Filipinas). Tan sólo un año después de establecerse Legazpi en Manila, en 1572, llegaron varios chinos con un cargamento de mercancías procedentes de su país, y en 1573 los primeros productos chinos cruzaron el Pacífico hasta Acapulco. El crecimiento de los sangleyes en Manila fue exponencial. Durante los siguientes años, los españoles se plantearon repetidamente establecerse en China desde Manila, de manera pacífica o por medio de las armas; sin embargo, con la instauración de la ruta del Galeón de Manila se hizo innecesario un enclave castellano en el continente. La capital filipina tuvo para los españoles el mismo papel que Macao para los portugueses. A principios del siglo XVII, decenas de miles de sangleyes vivían en la ciudad, lo que la convirtió prácticamente en un puerto chino de ultramar. La convivencia entre los chinos y los castellanos nunca fue fácil. ${ }^{11}$ Sin embargo, los españoles consiguieron el objetivo de establecer un vínculo con el gran imperio chino; al mismo tiempo, no tuvieron que abandonar Filipinas, y este país se convertiría, durante más de tres siglos, en el enclave asiático del imperio español.

\section{Bibliografía}

BARANDICA, Luis Abraham, “Andrés de Urdaneta en la Nueva España (1538-1568)”, en C. Barrón (coord.), Urdaneta novohispano. La inserción del mundo hispano en Asia, México, Universidad Iberoamericana, 2012, pp. 35-65.

BARRÓN, Cristina (coord.), Urdaneta novohispano. La inserción del mundo hispano en Asia, México, Universidad Iberoamericana, 2012.

${ }^{11}$ A lo largo del siglo XvII hubo varias rebeliones de los sangleyes de Manila seguidas de masacres de miles de chinos efectuadas por los castellanos. Algunas de las obras que han estudiado las relaciones entre los sangleyes y los españoles son, además de las ya citadas de Manel Ollé, la de Juan Gil, Los chinos de Manila. Siglos XVI y XVII, Lisboa, Centro Científico e Cultural de Macau, 2011, o la de Antonio García-Abásolo, "Españoles y chinos en Filipinas. Los fundamentos del comercio del Galeón de Manila”, en Félix Iñesta Mena, Felipe Lorenzana Lapuente y Francisco Mateos Ascacíbar (coords.), España, el Atlántico y el Pacífico: y otros estudios sobre Extremadura, Llerena, Sociedad Extremeña de Historia, 2013, pp. 9-29. 
Bernabéu, Salvador, El Pacífico Ilustrado: Del lago español a las grandes expediciones, Madrid, Mapfre, 1992.

"Carta de Legazpi al virrey de Nueva España, Panay, 25 de julio de 1570”, AGI, Patronato, 24. [www.upf.edu/asia/projectes/che/ s16/lega1570.htm, consultado en julio de 2016.]

"Carta del virrey de la Nueva España, Martín Enríquez, a Felipe II, 5 de diciembre de 1573”, AHN, Doc. Ind., Secc. Div., núm. 219. [www.upf.edu/asia/projectes/che/s16/virr1573.htm, consultado en junio de 2016.]

Folch, Dolors, "Biografía de Fray Martín de Rada", Revista Huarte de San Juan, Geografía e Historia, núm. 15, 2008, pp. 33-63.

García-Abásolo, Antonio, "Españoles y chinos en Filipinas. Los fundamentos del comercio del Galeón de Manila”, en Félix Iñesta Mena, Felipe Lorenzana Lapuente y Francisco Mateos Ascacíbar (coords.), España, el Atlántico y el Pacífico: y otros estudios sobre Extremadura, Llerena, Sociedad Extremeña de Historia, 2013, pp. 9-29.

GIL, Juan, "El primer tornaviaje", en S. Bernabéu (coord.), La nao de China, 1565-1815. Navegación, comercio e intercambios culturales, Sevilla, Universidad de Sevilla, 2013, pp. 25-64.

GIL, Juan, Los chinos de Manila. Siglos XVI y XVII, Lisboa, Centro Científico e Cultural de Macau, 2011.

GIL, Juan, Mitos y utopías del descubrimiento, vol. 2: El Pacífico, Madrid, Alianza Editorial, 1989.

Hidalgo, Patricio, "La figura de Andrés de Urdaneta en la historiografía indiana, conventual, documental y moderna", en S. Truchuelo (ed.), Andrés de Urdaneta: un hombre moderno, Ordizia, Ayuntamiento de Ordizia, 2009, pp. 17-91.

Hidalgo, Patricio, Los primeros de Filipinas. Crónicas de la conquista del archipiélago, Madrid, Miraguano y Polifemo, 1995.

Knauth, Lothar, "La cuenca del Pacífico: ‘...Una historia recuperada?”, en G. Cruz, C. Barrón, A. del Castillo y C. Hernández (coords.), El Galeón de Manila. Un mar de historias, México, JGH Editores, 1997, pp. 19-40.

Miguel, José Ramón de, Urdaneta y su tiempo, Ordizia, Ayuntamiento de Ordizia, 2008.

Ollé, Manel, La empresa de China. De la Armada Invencible al Galeón de Manila, Barcelona, Acantilado, 2002.

Ollé, Manel, La invención de China. Percepciones y estrategias filipinas respecto a China durante el siglo XVI, Wiesbaden, Harrassowitz Verlag, 2000.

OlLÉ, Manel, "La proyección de Fujien en Manila: los sangleyes del 
Parián y el comercio de la Nao de China”, en S. Bernabéu y C. Martínez Shaw (eds.), Un océano de seda y plata: el universo económico del Galeón de Manila, Sevilla, Consejo Superior de Investigaciones Científicas, 2013, pp. 155-178.

Rumeu de Armas, Antonio, El tratado de Tordesillas, Madrid, Mapfre, 1992.

SALES, Ostwald, El movimiento portuario de Acapulco. El protagonismo de Nueva España en la relación con Filipinas, 1587-1648, México, Plaza y Valdés, 2000.

SÁNchEZ, Jean-Nöel, “Tiempos Malucos. España y sus Islas de las Especias, 1565-1663”, en S. Truchuelo (ed.), Andrés de Urdaneta: un hombre moderno, Ordizia, Ayuntamiento de Ordizia, 2009, pp. 621-650.

ZHANG KaI, Historia de las relaciones sino-españolas, Beijing, Elephant Press, 2003. 
